\title{
REVIEW
}

\section{How Personal Experience Affects Perception of and Decisions Related to Climate Change: A Psychological View}

\author{
AdriAn BRÜGger, ${ }^{a}$ CHRISTINA DEMSKI, ${ }^{\mathrm{b}}$ AND STUART CAPSTICK ${ }^{\mathrm{b}}$

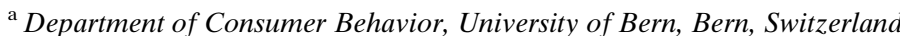 \\ ${ }^{\mathrm{b}}$ School of Psychology and Tyndall Centre for Climate Change Research, Cardiff University, Cardiff, United Kingdom
}

(Manuscript received 3 August 2020, in final form 8 February 2021)

\begin{abstract}
The proportion of the world's population exposed to above-average monthly temperatures has been rising consistently in recent decades and will continue to grow. This and similar trends make it more likely that people will personally experience extreme weather events and seasonal changes related to climate change. A question that follows from this is to what extent experiences may influence climate-related beliefs, attitudes, and the willingness to act. Although research is being done to examine the effects of such experiences, many of these studies have two important shortcomings. First, they propose effects of experiences but remain unclear on the psychological processes that underlie those effects. Second, if they do make assumptions about psychological processes, they do not typically corroborate them with empirical evidence. In other words, a considerable body of research in this field rests on relatively unfounded intuitions. To advance the theoretical understanding of how experiences of climate change could affect the motivation to act on climate change, we introduce a conceptual framework that organizes insights from psychology along three clusters of processes: 1) noticing and remembering, 2) mental representations, and 3) risk processing and decision-making. Within each of these steps, we identify and explicate psychological processes that could occur when people personally experience climate change, and we formulate theory-based, testable hypotheses. By making assumptions explicit and tying them to findings from basic and applied research from psychology, this paper provides a solid basis for future research and for advancing theory.
\end{abstract}

SIGNIFICANCE STATEMENT: A growing number of people experience environmental changes and weather events that are likely manifestations of human-made climate change (e.g., heat waves, wildfires, or floods). Research has started to examine whether experiencing events influences how ordinary people feel about climate change and possible measures to reduce its extent and to adapt to its consequences. The purpose of this review is to identify and explain in detail psychological processes that could occur when people personally experience climate change and formulate theorybased, testable hypotheses that focus on three clusters of processes (noticing and remembering, mental representations, and decision-making). This work provides a solid basis for future research and for advancing theory.

KEYWORDS: Social Science; Extreme events; Communications/decision making; Decision support; Education; Societal impacts

\section{Introduction}

For nonexperts, climate change is difficult to grasp. The definition of climate as the average weather over a duration of decades makes climate change an inherently statistical phenomenon that, strictly speaking, human beings are unable to experience in any immediate sense. Yet, people are able to experience the consequences of environmental and climatic changes. For instance, climate change increases the number of people who are exposed to above-average monthly temperatures, La Niña events, thunderstorms, and wildfires and thus makes it more likely that people will personally experience extreme weather events and seasonal changes related to climate change (Cai et al. 2015; Lehner and Stocker 2015; Lin et al. 2012). Research is increasingly being done to examine how people experience and interpret such weather phenomena

Corresponding author: Adrian Brügger, adrian.bruegger@ imu.unibe.ch that can plausibly be linked to the impacts of climate change; for example, discrete extreme weather events (Demski et al. 2017; Spence et al. 2011) or changes in the seasons (McCright et al. 2014; Taylor et al. 2014).

Whether directly attributable to climatic change or not, such experiences have the potential to change beliefs, attitudes, and behaviors by rendering this otherwise abstract phenomenon in terms familiar and concrete (Nicholson-Cole 2005). The empirical evidence for these assumptions is mixed: while some studies support a hypothesized impact of experience on perceptions and behaviors (Demski et al. 2017; Spence et al. 2011), others have not observed this (Dessai and Sims 2010; Whitmarsh 2008; for a review, see Howe et al. 2019).

Irrespective of empirical findings, many of these studies focus on establishing whether an effect of experience exists and remain unclear about when and how personally experiencing climate change can alter people's perceptions and behaviors, and what is constituted by the "experience" of climate change. Instead, the focus has been on establishing whether the link 
exists or not (for examples, see Howe et al. 2019). A lack of clarity about the process by which experience affects people leaves open the question of which types of event will be consequential and under which circumstances. There is emerging evidence, for example, that for those who feel able to cope with extreme weather events, experience is less likely to have an emotional effect and to translate into intentions to act on climate change (Ogunbode et al. 2019). To advance the understanding of how personal experiences of climate change may affect people, the present article makes a case for a stronger engagement with theory and provides a novel and comprehensive framework that integrates theoretical contributions and empirical findings from across psychology and related disciplines. The increased connection to psychological theory enables researchers to go beyond the question of whether or not there is a link between experiences and individual responses to climate change: it provides a solid basis to formulate testable hypotheses about when and how experiences are likely to trigger different types of cognitive, emotional, and behavioral responses. Table 1 provides specific hypotheses (if enough information is available to formulate expectations) and research questions (if it is less clear what to expect) for the discussed processes.

Our approach begins by describing factors that affect basic awareness of an experience (i.e., whether people notice and remember it). We then focus on interactions between experiences and mental representations, that is, how existing mental representations may influence the processing of experiences and how experiences may, in turn, alter how people think about climate change. Next, we consider how experiences related to climate change may affect the processing of risks and decision-making. Moreover, to reflect that personal experiences do not happen in a vacuum but rather within the context of individuals' preexisting views and predispositions, we consider how personal characteristics may influence each of the three clusters of processes.

In short, the framework identifies possible psychological processes through which experiences of climate change may affect people's perceptions and behaviors and substantiates these processes with findings from basic and applied research. As such, the present article enables a more systematic and theory-based consideration of the effects of climate change experiences and opens up promising avenues for future research and theory development.

\section{A process-oriented conceptual framework to understand the role of experiencing climate change}

We propose that the defining characteristic of a potential personal "experience" of climate change be that it can be detected with one's own senses. Such experiences can include environmental changes (e.g., glacier retreat, observable changes to animal and plant life) and single or relatively short-lived events (e.g., heat waves, floods). By contrast, if an experience is mediated through reports from other people or the media, then for the purposes of the framework considered here such an event cannot be considered to be a direct personal experience. Also, being resident in an area that has been exposed to climate change is not equated with personal experience in our framework. As we will show in more detail below, for an event to qualify as a personal experience in psychological terms, people need to subjectively notice and further process the event or change.

One defining aspect of an experience that warrants attention is its valence. Climate change experiences can, in principle, be perceived as negative, as neutral, or even positive. Nonetheless, the impacts of climate change are predominantly negative (O'Neill et al. 2017), as are public perceptions thereof (Steentjes et al. 2017; Whitmarsh and Capstick 2018). Moreover, adverse experiences signal that something is wrong and that action is required (Levine and Pizarro 2004) and so are more likely to motivate change. Taken together, experiences that are perceived as negative are more likely to occur with climate change and to increase people's willingness to mitigate and adapt. This article will therefore focus on experiences that are perceived as negative (e.g., anxiety-provoking, threatening, distressing; Demski et al. 2017).

To understand when and how experiences motivate people to respond to climate change, we draw on established psychological theories and empirical findings and organize them in three clusters of processes (for a similar model in the context of risk communication, see Bostrom et al. 2018). First, noticing and remembering deals with factors that affect the probability that people become aware of and remember climate-related events. Some characteristics of an event, such as magnitude, frequency, or distinctiveness, may directly capture people's attention. The extent to which people attend to personal experiences may not only depend on the characteristics of an event, but also on social processes. The second cluster comprises processes related to mental representations, including how mental representations may influence the processing of experiences and how experiences may change existing beliefs, knowledge, and subjective mental models of climate change. Processing of risks and decision-making is the third cluster of processes and describes how experiences may affect decisions via different cognitive processes.

These three clusters can be understood as processes that occur when people process the sensory information elicited by climate-related events. While triggered by sensory information, nevertheless these processes occur within the context of existing mental representations and predispositions, including memories of previous events, acquired knowledge, beliefs, values, worldviews, attitudes, and preferences (Brod et al. 2013; Kahan et al. 2011). A crucial implication of this is that existing individual predispositions (e.g., beliefs and values), particularly with respect to climate change, may affect the interpretation of new experiences, their integration into existing mental representations, and their effect on decisions (Alberini and LeDoux 2013; Myers et al. 2013). Thus, in addition to bottom-up effects there are also topdown effects, which we also consider.

\section{a. Noticing and remembering}

Living in a place that has been exposed to an event that qualifies as a potential experience of climate change does 
not guarantee that people process the event further. For further processing to happen, it is essential that they pay attention to the event in the first place, which depends on various factors. To some extent a climate-related event's objective characteristics can predict whether people attend to it. One such characteristic is the sensory accessibility of climaterelated events. Some, such as temperature extremes, are quite difficult to reliably detect with one's senses, although a range of evidence does suggest that climate change perceptions can follow temperature anomalies over time (e.g., Donner and McDaniels 2013; Egan and Mullin 2012; Hamilton and Stampone 2013). Conversely, events such as flooding involve multiple senses simultaneously (water can be touched, seen, smelled) and are therefore more likely to be noticed (for empirical evidence that supports this reasoning, see Goebbert et al. 2012). Moreover, extreme weather events that occur suddenly (e.g., hurricanes) are more noticeable and remembered more accurately than events that have slower and more gradual onsets (e.g., droughts; Howe et al. 2014; Maas et al. 2020; Ripberger et al. 2017; Shao 2016; Yantis 1993). One explanation for this is that the signals from fast-onset events are much clearer than those of gradual events.

Other event characteristics likely to capture people's attention include magnitude and frequency (Howe et al. 2014). The larger an event is and the more frequently it occurs, the more likely it is that there will be stronger and clearer environmental signals (e.g., water covering tracts of farmland, high winds, death of plants and animals). Such events also increase the risk that people personally suffer harm, which in turn increases the likelihood that such experiences are retained in memory.

Although the objective characteristics of an event help to predict whether people notice it, it is also important to examine more subjective aspects of how people process climate-related events. Three factors that can affect whether people notice and remember an event are the extent to which they perceive it as distinct, personally relevant, and emotionally salient.

Distinctiveness refers to the subjective representation of a particular event or object as being unusual or noticeable (Hunt 2006). An event can attract attention in one of two ways (Craik 2006; Hunt 2006): first, with respect to its immediate context (Schmidt 1991), such as a hail shower on an otherwise sunny day; and second, when compared to previous experiences in a person's long-term memory (McDaniel and Geraci 2006; Schmidt 1991). For instance, the same hail shower could strike a person as unusual because it is different from those that they have previously experienced.

A key feature of these two forms of distinctiveness is that they are both relative to a person's own prior experiences and expectations (Hunt 2006). This is in line with the finding that the degree of abnormality or unexpectedness is a significant predictor of attention to climate-related events (Sisco et al. 2017). A question that follows from this is if and how long-term changes to an environment may affect the perception of what is normal versus unusual and lead to different perceptions between succeeding generations (i.e., shifting baseline; see, e.g., Hamilton et al. 2018; Klein and Thurstan 2016; Moore et al. 2019).
Importantly, distinctiveness also affects how well people remember an event. Both controlled laboratory experiments (Geraci and Rajaram 2002; Schmidt 1985) and autobiographical studies (Catal and Fitzgerald 2004) show that people recall objects and events better if they experience them as distinct (i.e., as being unusual or noticeable; cf. Hunt 2006).

In a related way, personal relevance-that is, the extent to which an event is important, consequential, or otherwise relevant to oneself-likewise affects attention and memory (Conway 2005; Tomaszczyk et al. 2008). If an event has consequences that matter to a person in some way, it is likely to receive attention. Of course, what is considered to be personally relevant depends on preexisting dispositions (e.g., preferences, worldviews, see end of this section for a more detailed discussion), and the extent to which a person extrapolates from direct experience to draw conclusions about broader impacts-a pattern that is consistent with the more general self-reference effect in memory research (Kesebir and Oishi 2010; Rogers et al. 1977).

A third attribute of experiences that affects attention and memory is the extent to which they involve emotions. Emotional stimuli capture our attention and therefore tend to be detected faster and hold attention for longer (Levine and Edelstein 2009; Reisberg 2006). In addition, emotionally salient stimuli tend to enhance information processing and deepen their encoding in memory. Overall, emotional intensity is associated with longlasting, vivid, and accurate memories (Canli et al. 2000; Talarico et al. 2004).

An increasing number of studies have considered the role of emotion in processing information and decision-making about climate change (Chapman et al. 2017), and wider psychological research consistently points to the importance of emotions in consolidating memory (Hoscheidt et al. 2013; Laney et al. 2004). On the other hand, there is also evidence suggesting that intense negative emotions may impair memory performance (Deffenbacher et al. 2004; Hoscheidt et al. 2013).

One explanation for these apparently incompatible findings is that examining only the valence of emotions may be too simplistic. Empirical evidence suggests that discrete emotions are associated with different goals and that these goals strongly influence which aspects of an event are deemed relevant, attended to, and remembered: a frightened person is likely to focus on and remember threat-related information, whereas a sad person's attention and memory revolves around what was lost, damaged, or missed (Levine and Burgess 1997; Levine and Edelstein 2009; Levine and Pizarro 2004; DeSteno et al. 2004). Negative emotional responses (including anger and anxiety) have similarly been found to play a specific role in mediating the influence of direct experience of climate impacts upon attitudes and intentions (Demski et al. 2017). There are also different implications for the way people understand the need or nature for action on climate change, depending on whether emotional responses are prospective (e.g., fear for the future), retrospective (e.g., sadness at loss), and whether they are linked to a sense of what is moral or ethical (e.g., anger at others perceived to be responsible for harm; Böhm 2003).

An event's characteristics are not the only factors that determine whether people notice and remember it. People's 
TABLE 1. Personal experiences of climate-relevant events: Overview of theoretically plausible direct and indirect effects and research questions.

Focal process

Noticing and remembering

Sensory accessibility

Sudden vs slow and gradual onset Sudden events are more likely to be noticed and remembered than those with slow and gradual

Magnitude and frequency

Distinctiveness

Personal relevance

Emotions

Top-down effects of mental representations

Social and cultural processes

\section{Mental representations}

The more senses that an event stimulates, the more likely people are to notice and remember it onsets (number of senses involved)

The more intensively that an event stimulates people's senses, the more likely it is that they notice and remember it (intensity of stimulation)

Memories of sudden events are more accurate than those of more gradual events

The greater in magnitude and the more frequent an event is, the higher the likelihood is that people notice and remember it

Events that are perceived as unusual with respect to previous experiences and expectations should attract more attention and be remembered better than those that are perceived as usual

To what extent do long-term climate-related changes in the environment shift the baseline of what is normal vs unusual?

The more important, consequential, or otherwise relevant to a person (based on preexisting views, preferences, and other important personal characteristics) that an event is, the more likely it is to be noticed and remembered

Strong objections about climate change or its consequences (i.e., personal relevance in a "negative sense") should increase the rejection or downplay of links between experienced events and climate change and decrease awareness and memory

Variations in personal relevance (e.g., because of different interests, political positions, or cherished values) are likely to moderate several of the discussed processes (e.g., emotional involvement, consumption of media, and discussion with peers)

Emotionally charged events (events that trigger strong emotional responses) are more likely to be noticed than are emotionally neutral events

Emotionally charged events should result in longer-lasting, more vivid and accurate memories than emotionally neutral events do

Do emotions impair memory of an event if they exceed a certain level of intensity?

To what extent do effects of specific, discrete emotions vary (e.g., with respect to memory, motivation, behavior)?

Are there processes by which emotional responses impede a behavioral response to climate change?

People are more likely to notice and remember events that are consistent with what they know and expect

To some extent this hypothesis conflicts with the "distinctiveness" hypothesis (that unusual events lead to more attention and better memory) and raises the following questions:

Is there a general tendency for either expected or unusual events to lead to more attention and better memories?

Or are there some circumstances under which expected vs unusual events lead to more attention and better memories?

Public attention (e.g., climate-related events being discussed in the media, by elite figures, or among peers) should increase the likelihood that people notice and remember an event

Possible mechanisms that improve memory are, e.g., repetition (rehearsal) or increased depth of processing

Experiences that are consistent with what people know and expect strengthen existing mental representations and make them more accessible

Strengthened mental representations increase people's confidence about their views and, in turn, the consistency between their views and their behavior

Experiences that conflict with existing mental representations lead to discomfort and the motivation to reduce this state (e.g., by assimilation, accommodation, or motivated reasoning)

When the new experience is similar to any existing mental representation or the willingness to engage in effortful processing is low, it leads to a reinterpretation of the event that is consistent with existing mental representations and expectations (assimilation)

When the new experience differs strongly from existing mental representations and the willingness to engage in effortful processing is high, it leads to a revision of the mental representations and expectations to include the new experience (accommodation)

When an experience conflicts with a person's established worldview, identity, values, or other important personal characteristics, they are likely to engage in motivated reasoning

Those who have experienced extreme weather events will be more likely to spontaneously connect associated imagery (e.g., flooding or storms) with the idea of climate change than will those who have not 
TABLE 1. (Continued)

\begin{tabular}{ll}
\hline \hline \multicolumn{1}{c}{ Focal process } & Theoretically plausible hypotheses and research questions \\
\hline $\begin{array}{l}\text { Effects on decision-making } \\
\text { Risk perceptions }\end{array}$ & (Severe enough) personal experiences of climate-related events should increase risk perceptions \\
(i.e., the perceived likelihood of similar and related future events) \\
Increased risk perceptions should trigger negative emotions (e.g., fear) \\
Negative emotions should increase the motivation to seek information and to carefully \\
(systematically) process information \\
Negative emotions \\
Negative emotions should lead to behaviors aimed at reducing the risk when the perceived \\
self-efficacy is high \\
Negative emotions should lead to coping strategies that reduce the negative emotions (but not \\
the risk) when the perceived self-efficacy is low \\
How are negative emotions influenced by personal characteristics/individual differences? \\
When does systematic processing increase the willingness to mitigate and adapt to climate change? \\
How does this depend, e.g., on the quality of the information or personal characteristics/existing \\
individual differences?
\end{tabular}

attention to an event-and their personal, visceral experience thereof-may also be guided by social processes. For example, people may become aware of an event when they hear or read about it in the media (including the weather report; Bloodhart et al. 2015), when elite figures such as politicians talk about it (Carmichael and Brulle 2017), or when their peers (e.g., friends, family, and colleagues) mention it. It is important to acknowledge here that even though people's attention is directed toward an event by others, we are still considering only events that people experience themselves.

Social and societal processes (including discussing one's own experiences or being reminded of them by media reports) also have the potential to affect memory processes. The more people think and talk about an event (what psychologists refer to as its rehearsal), the more likely it is that connections are created between the new information and existing mental representations. As such, the level of processing of a personally experienced event becomes deeper, leading to an increased likelihood of retrieving the information in the future (Burgess and Weaver 2003; Bohannon 1988). In line with this, the Social Amplification of Risk Framework (SARF; see Kasperson and Kasperson 2005; Pidgeon et al. 2003) describes how the strength of the (risk) signal associated with a particular occurrence (e.g., an extreme weather event) that has been perceived through the senses can be amplified or attenuated by a number of social processes and social actors (institutional, political, mass media, etc.; Renn 2011). Considering the SARF, one's perception of climate risks is partly related to direct personal experience but is also fed into a process whereby persons and groups interpret (and thereby attenuate or amplify) risks in accordance with individual-level processes such as heuristics, and social processes such as group membership and political context. Particularly in the case of extreme weather events, which receive widespread attention and media commentary, processes of social amplification may render personal experience especially salient and memorable (Gavin and Marshall 2011), which could lead to individual-level attitude change and larger-scale consequences such as political action or social protest (Renn 2011). This is supported by the finding that climate change is more readily available in people's minds when media coverage is high versus low (Brulle et al. 2012). While the SARF approach does not provide clear predictions about which events may be amplified or attenuated-for example, why certain extreme weather events receive a high level of prominence while others may be overlooked-Renn (2011) has argued that this can be complemented through the further application of resonance theory. From this perspective, the experience of extreme weather events would be expected to be amplified or to have particular salience for a person if they resonated with one of the four dominant systems that structure society: politics, economy, culture, and social relationships. For example, if an event is understood in terms of empathy with others who have been affected (social relationships) or the risk of financial losses (economy), it is more likely to be amplified and so become prominent in people's concerns.

As already alluded to, the processes described in this section are likely to vary as a function of people's views and preferences. For instance, it can be assumed that the more people care about things that are threatened by climate change, the more likely they are to engage with these things, monitor their state, be emotionally involved, seek relevant information (see section on decision-making and behavior), and discuss them with others. By extension, they should be more likely to notice and remember relevant events. However, if personally relevant links to climate are absent or if people who hold values or beliefs that conflict with the acknowledgment of climate change, they may reject or downplay links between experienced events and climate change and therefore notice and remember them less well (Bohr 2017; Capstick and Pidgeon 2014; Howe and Leiserowitz 2013; Kahan et al. 2011; McCright et al. 2014). Similar top-down influences may occur in socially driven attention and memory processes. For example, by choosing friends who share similar interests and media outlets that align with one's values (Arendt et al. 2019; Bolsen and Leeper 2013; Brannon et al. 2007; Frimer et al. 2017; Knobloch-Westerwick and Meng 2009; Lönnqvist and Itkonen 2016), people create contexts in which the type of information they receive varies systematically. This implies that the extent to which people's attention is directed toward climate-related events and the corresponding likelihood to notice and remember personal experiences depends on their social and media environment. 


\section{b. Personal experiences and existing mental representations}

The extent to which personal experiences match existing mental representations affects how people process the new experience. For example, if people have a mental model (Bostrom et al. 1994) in which climate change causes extreme weather events, they are more prepared to notice such events and connect personal experiences of flooding, hurricanes, and the like with climate change than are people who have mental models in which extreme events and climate change are not connected (Capstick and Pidgeon 2014). Similarly, when a person has experienced a comparable event before, this is likely to be included as an additional memory within the network of existing mental representations. An experience that is consistent with what people know and expect can make these mental representations stronger and more accessible (Anderson 1983). Assuming that this makes people more confident about their views, the experience can also increase the consistency between people's views and their behavior (Tormala and Rucker 2007). Thus, climate-related experiences that are consistent with people's mental representations could provide the additional evidence that is necessary to turn uncertain views into firm convictions that guide behavior (for a similar argument, see Myers et al. 2013).

By contrast, when the new experience conflicts with existing mental representations, people are likely to experience a state of imbalance that they will try to reduce (Piaget and Cook 1952; Proulx et al. 2012). Two strategies that can resolve such states of imbalance are assimilation and accommodation (Illeris 2006; Piaget and Cook 1952; Proulx and Heine 2010; Proulx et al. 2012).

Assimilation is the process by which people link a new experience to existing mental representations without the need to change what they already know or believe. Take for example, an exceptional heat wave in spring. A person who assimilates this information may interpret the heat wave as a rare atmospheric phenomenon that is unlikely to repeat itself, or as part of the natural annual variability in temperature over time-the underlying mental representation of spring remains unchanged.

Accommodation, the second strategy to reduce imbalance, occurs when people create a new mental representation or modify existing ones so that they are consistent with the new experience. Accommodation typically takes places when (i) a new experience is too different to relate to any existing mental representation, and (ii) the person has the necessary motivation to engage in this mentally effortful process (Illeris 2006; Piaget and Cook 1952; Proulx and Heine 2010; Proulx et al. 2012). To illustrate, a person who accommodates the experience of a spring heat wave may link the event to climate change in a way that they have not done before and revise their expectations of what temperatures a typical spring may bring in the future.

A parallel literature on "social representations" has considered the ways in which people understand and modify their understanding of phenomena via mental representations. In this framework, representations are individually held (in mind) yet also socially shared via commonplace concepts, imagery, and metaphors (Breakwell 2001; Smith and Joffe 2013).
From the perspective of social representations theory, new information-as in the case of direct experience with an extreme weather event - is incorporated into existing understanding via anchoring and objectification. Anchoring is a process whereby new information is categorized and made familiar; for example, the abstract, technical concept of climate change is conceptualized via more everyday ideas about the weather and other environmental issues. Objectification translates new concepts into more concrete images and symbols, such as heat waves or melting glaciers in the case of climate change. Smith and Joffe $(2009,2013)$ suggest that flooded landscapes have been used by the media in the United Kingdom in a way that makes the risk of climate change more concrete by offering a tangible, visible "proof" that climate change is occurring.

The possibility that a person may revise their mental representations in principle should not create the impression that this is done lightly. Changing mental representations (i.e., accommodation) requires substantial cognitive resources, and so assimilation might be a more appealing and convenient option (Block 1982; Illeris 2006; Proulx and Heine 2010). Empirical evidence suggests that individuals' mental representations can be very stable across time (Krosnick and Alwin 1989) and resistant to change (Ross et al. 1975) —especially if people feel confident about their views (Tormala and Rucker 2007) and if these are central to the individual's identity or values (Krosnick 1988; Zuwerink and Devine 1996). In this case there is a high chance that people will engage in processes that allow them to maintain their existing mental representations. This can include the tendency to selectively attend to and interpret information that is consistent with one's beliefs and attitudes, a process known as motivated reasoning (Frimer et al. 2017; Kunda 1990; Washburn and Skitka 2017). Through such behaviors people can also evade information that does not fit into their existing cognitive structures and avoid having to engage in effortful counterargumentation or even having to change their attitudes and beliefs (Hart et al. 2009). Importantly, several studies suggest that such motivated processing occurs in the context of climate-related personal experiences (Broomell et al. 2017; Capstick and Pidgeon 2014; Fownes and Allred 2018; Hamilton et al. 2018; Hazlett and Mildenberger 2020; Myers et al. 2013; Shao and Goidel 2016).

In short, existing mental representations can influence the way events are noticed, interpreted, and remembered by providing expectations and interpretive frames (Ghosh and Gilboa 2014; Swim et al. 2010). An unspectacular experience might be enough to change the mental representation of a person who does not hold strong views about climate change, while not even the most dramatic experience can change how a firm skeptic thinks about climate change.

\section{c. Effects of experience on risk processing and decision-making}

To learn more about how experiences may affect behavior, it is helpful to turn to research on how people make risk decisions. In what follows, we discuss the role of experiences within two types of risk decision-making models.

The first of these theoretical perspectives is the Risk Information Seeking and Processing model (RISP; Griffin 
et al. 1999; Yang et al. 2015). In the RISP model, personal experiences are likely to increase risk perception, that is the belief that one is personally susceptible to a risk (sometimes also referred to as personal relevance, issue salience, or personal involvement). This, in turn, should trigger negative emotions and increase the motivation to evaluate one's level of knowledge, seek information (if necessary) and to think carefully about the available relevant information (systematic processing; see also Petty and Cacioppo 1986). More elaborated processing should then increase the willingness to change one's behavior and to support relevant policies (Griffin et al. 1999; Yang et al. 2015, 2014).

There is evidence for most of these processes. For instance, people who have previously experienced flooding tend to rate the risk of being affected by similar events in the future as higher than people without prior experience of flooding (Grothmann and Reusswig 2006; Lawrence et al. 2014; Zaalberg et al. 2009; for more examples in other contexts, see Dunn et al. 2016; Knuth et al. 2014; Lujala et al. 2015; Wachinger et al. 2013). The effects of such extreme weather experiences may go beyond the immediate context of specific events such as flooding and affect how people more generally think about risks of climate change: people who have experienced flooding tend to perceive personal and local climate risks to be higher (Demski et al. 2017; Spence et al. 2011; van der Linden 2014, 2015).

The links between risk perceptions and negative emotions are also documented, both with respect to specific hazards (Keller et al. 2006; Zaalberg et al. 2009) and with respect to the broader phenomenon of climate change (Leiserowitz 2006; Ogunbode et al. 2019, 2020; Smith and Leiserowitz 2014; Sundblad et al. 2007; van der Linden 2014, 2015). Similarly, there is some evidence suggesting that negative emotions about climate change and risk perceptions increase information seeking and systematic processing (Meijnders et al. 2001; Yang et al. 2014, 2015). Evidence for the direct and indirect links between personal experiences and behavior (including policy support) is mixed (Demski et al. 2017; Dessai and Sims 2010; Grothmann and Reusswig 2006; Hazlett and Mildenberger 2020; Ogunbode et al. 2019; Spence et al. 2011; Whitmarsh 2008; Zaalberg et al. 2009). This could be due to methodical choices, such as which constructs were included in the studies or how they were operationalized (e.g., specific vs general risks and perceptions).

A more theoretical explanation for the mixed evidence is that there are different underlying mechanisms by which experience is or is not translated into action. For instance, whether or not people come to see climate change as a relevant risk that requires action is contingent on the nature of the information that their decision is based on: the more compelling the information available from an experience (including its objective and subjective features, as discussed above), the more high-effort thinking should lead to the view that this issue is a risk that requires action (Meijnders et al. 2001; Petty et al. 1995). Conversely, if people encounter information that, for them, convincingly raises doubts about the relevance of climate change and the necessity to act, in-depth thinking can also decrease people's willingness to do so.
As with processes related to noticing, remembering, and mental representations, preexisting beliefs and preferences could influence the interpretation of information and its influence in decision-making processes. Some research suggests that those with high levels of scientific numeracy may be most motivated and able to apply new information in a way that fits with their preexisting views on climate change, whether to "use" or "explain away" the new evidence (Kahan et al. 2012). High-effort processing could actually increase such (polarizing) tendencies because it makes decisions that are consistent with preexisting beliefs and preferences more likely (Fischer and Glenk 2011).

There is a second set of risk decision-making models that can be useful to explain the effects of personal experiences on behavior. These models focus on how people respond to threatening information and has a strong focus on the emotion of fear. Converging evidence from theories about health and risk communication (Floyd et al. 2000; Maloney et al. 2011; Rogers 1975; Sheeran et al. 2014) suggests that people ask themselves two types of questions when they process threatening information: they first appraise the level of threat by evaluating its severity and the chances that they could personally be affected by it. When individuals believe that they are safe, they will not process the information further. If, on the other hand, they feel that there is a severe enough threat to them personally, they are likely to be motivated to address a resulting fear response.

A sense of being threatened initiates the second appraisal process, in which people consider their coping options by evaluating the effectiveness of possible remedies and their ability to implement them. The result of this second appraisal process determines how individuals reduce their fear: if they believe that they are able to take steps that effectively reduce or avert the threat (self-efficacy), individuals are likely to reduce their fear by tackling the threat directly through changes in their intentions and behaviors. For example, if a person can take effective action to remove themselves from the path of a dangerous storm, they are likely to do so. Alternatively, if individuals conclude that they are unable to effectively address a threat, they may engage in coping strategies that reduce their fear rather than addressing the threat itself; this can include ignoring or downplaying the threat (Floyd et al. 2000; Maloney et al. 2011).

As a general rule, it can be assumed that people will evaluate minor climate events (e.g., small and slow developments such as incremental temperature increases or changes in rainfall patterns) as inconsequential to them directly and not further process their experience in terms of a fear response. By contrast, more extreme events are more likely to be perceived as severe and to be processed further (Howe et al. 2014).

Again, the course of action that people take will, in part, depend on their self-efficacy beliefs, which are shaped by a person's history and past experiences (Floyd et al. 2000). When people successfully avert or reduce a climate change-related threat through deliberate behaviors, their self-efficacy beliefs should become stronger and the likelihood of them tackling such threats in the future should increase. By contrast, if people fail to perceive that they have been able to personally reduce a threat, their self-efficacy beliefs are likely to 
decrease and lead them toward responses that reduce the negative emotions associated with the threat but not the threat itself (Floyd et al. 2000; Maloney et al. 2011; Seligman 1975). In the case of extreme weather, it is highly questionable whether individuals can actually take action that reduces the likelihood of these being influenced by climate change-and yet research has shown that people perceive themselves to have the ability to reduce the risks of climate change by changing their behavior, which in turn predicts their behavioral intentions (Spence et al. 2011).

\section{Discussion}

To understand how personal experiences affect perceptions of climate change and the willingness to act as individuals, it is crucial to carefully examine the psychological processes that can be triggered by personal experiences and that may in turn influence the processing of such experiences. The present article has organized established theoretical contributions and empirical findings from psychology and other social sciences in a comprehensive framework consisting of three clusters of psychological processes: 1) whether and how people notice and remember an experience, 2) how the experience may be influenced by and affect mental representations (e.g., beliefs about climate change), and 3) how an experience affects risk processing and decision-making. Moreover, we discuss how existing individual predispositions (e.g., beliefs and values) may moderate these processes.

To sum up, the consideration of these three clusters of intertwined psychological processes suggests that personal experiences of climate change-related events can influence how people think and feel about this issue and how they are likely to act. Yet it is crucial to note that much beyond the actual occurrence of a climate-related or extreme weather event needs to happen for a single experience to change mental representations or alter people's behavior. This also challenges, although does not preclude, the notion that experiencing a single climate-related event can, like a switch, significantly change the way a person feels about the issue.

There are several ways in which future research could build on the present paper. First, specific aspects of the proposed processes could be tested in detail. For instance, researchers could conduct a longitudinal study to examine when and how mental representations change and how persistent these changes are. This would help to understand the conditions under which people incorporate climate-related changes (e.g., frequency of extreme events or disruptions of the seasons) into their existing beliefs and to distinguish between short- and long-term effects (see Capstick et al. 2015). Researchers could also explore ways to experimentally test the proposed processes, for example by exposing people to different types of personal climate experiences using virtual reality tools (Breves and Schramm 2021; Fauville et al. 2020; Petersen et al. 2020). To facilitate the planning of future studies, we provided specific hypotheses and research questions for the discussed processes (Table 1).

Second, future research could explore the sequence of the proposed processes and their relationships. For didactic simplicity, we have discussed one theoretical perspective at a time. However, the processes we propose do not necessarily occur in the suggested order and they may influence each other in various ways. For instance, we noted that having successfully averted climate-related risks in the past can influence a person's perceptions of their ability to act and thereby affect their course of action (see Ogunbode et al. 2019). That is, decisions and behavior should not be exclusively thought of as the last element in a causal chain, but also as an important source of information for future behavior.

A third avenue for future research could be to distinguish between different types of climate change actions. For instance, some of the processes outlined in the present framework may be different for mitigation (i.e., steps intended to reduce the extent of climate change) and adaptation (i.e., steps to prepare and deal with its negative effects). To illustrate, theories that are interested in how people react to threatening information typically use self-protective behaviors as outcome variables. Conceptually, this focus is more closely related to adaptation-where the goal is to prevent or reduce damages - than to mitigation. Future research could investigate the extent to which different theories and models can explain mitigation and adaptation behaviors (including private sphere, public sphere, and political behavior; see, e.g., Stern 2000) and refine the framework presented here. Another approach would be to examine how lay people understand and categorize different types of behaviors and whether these are guided by different processes (for an example in the context of energy transition, see Böhm et al. 2019).

A fourth avenue for future research could be to compare different types of experiences. In this article, personal experiences were defined as experiences that are detectable with one's own senses. However, it could also be argued that people are capable to empathize with others and that their accounts (i.e., vicarious experiences) may trigger processes similar to those described in this article (e.g., emotions such as sadness or fear).

Fifth, although the framework presented in this article includes a comprehensive set of processes, it is not exhaustive and there are several ways in which it could be extended by future research. For example, research on trauma and mental health offers an additional perspective that could help to understand people's perceptions of extreme events and their behaviors regarding climate change (Berry et al. 2010; Cunsolo and Ellis 2018; Fritze et al. 2008).

To conclude, a key contribution of this article is that the effect of experiences is more complex and nuanced than is commonly assumed in the literature. Experience may very well be "the best teacher" (Akerlof et al. 2013; see also Reser et al. 2014), but people also have a tendency to succumb to processes by which "believing is seeing" (Lorenzoni and Hulme 2009). To understand when and how experiences are consequential, it is important to acknowledge the multifaceted processes they can involve and give rise to rather than to base research projects or campaigns on our own intuitive mental models of how people process information-for example, that if only "proof", is provided of climate change, this will lead to attitude change. Only through detailed empirical study of the psychological and 
social processes and their contingencies can the effects of personal experiences be thoroughly understood.

Acknowledgments. The authors thank two anonymous reviewers for their critical evaluation of an earlier version of this paper and their constructive criticism.

\section{REFERENCES}

Akerlof, K., E. W. Maibach, D. Fitzgerald, A. Y. Cedeno, and A. Neuman, 2013: Do people "personally experience" global warming, and if so how, and does it matter? Global Environ Change, 23, 81-91, https://doi.org/10.1016/j.gloenvcha.2012.07.006.

Alberini, C. M., and J. E. LeDoux, 2013: Memory reconsolidation. Curr. Biol., 23, R746-R750, https://doi.org/ 10.1016/j.cub.2013.06.046.

Anderson, J. R., 1983: The Architecture of Cognition. Harvard University Press, 345 pp.

Arendt, F., T. Northup, and L. Camaj, 2019: Selective exposure and news media brands: Implicit and explicit attitudes as predictors of news choice. Media Psychol., 22, 526-543, https:// doi.org/10.1080/15213269.2017.1338963.

Berry, H. L., K. Bowen, and T. Kjellstrom, 2010: Climate change and mental health: A causal pathways framework. Int. J. Public Health, 55, 123-132, https://doi.org/10.1007/s00038-009-0112-0.

Block, J., 1982: Assimilation, accommodation, and the dynamics of personality development. Child Dev., 53, 281-295, https:// doi.org/10.2307/1128971.

Bloodhart, B., E. Maibach, T. Myers, and X. Zhao, 2015: Local climate experts: The influence of local TV weather information on climate change perceptions. PLOS ONE, 10, e0141526, https:// doi.org/10.1371/journal.pone.0141526.

Bohannon, J. N., 1988: Flashbulb memories for the space shuttle disaster: A tale of two theories. Cognition, 29, 179-196, https:// doi.org/10.1016/0010-0277(88)90036-4.

Böhm, G., 2003: Emotional reactions to environmental risks: Consequentialist versus ethical evaluation. J. Environ. Psychol., 23, 199-212, https://doi.org/10.1016/S0272-4944(02)00114-7.

_, R. Doran, A. Rødeseike, and H.-R. Pfister, 2019: Pathways to energy transition: A faceted taxonomy. Int. Stud. Manage. Organ., 49, 303-319, https://doi.org/10.1080/00208825.2019.1623981.

Bohr, J., 2017: Is it hot in here or is it just me? Temperature anomalies and political polarization over global warming in the American public. Climatic Change, 142, 271-285, https:// doi.org/10.1007/s10584-017-1934-Z

Bolsen, T., and T. J. Leeper, 2013: Self-interest and attention to news among issue publics. Polit. Commun., 30, 329-348, https://doi.org/10.1080/10584609.2012.737428.

Bostrom, A., M. G. Morgan, B. Fischhoff, and D. Read, 1994: What do people know about global climate change? 1. Mental models. Risk Anal., 14, 959-970, https://doi.org/10.1111/j.15396924.1994.tb00065.x.

, G. Böhm, and R. E. O'Connor, 2018: Communicating risks: Principles and challenges. Psychological Perspectives on Risk and Risk Analysis: Theory, Models, and Applications, M. Raue, E. Lermer, and B. Streicher, Eds., Springer, 251-277.

Brannon, L. A., M. J. Tagler, and A. H. Eagly, 2007: The moderating role of attitude strength in selective exposure to information. J. Exp. Soc. Psychol., 43, 611-617, https://doi.org/ 10.1016/j.jesp.2006.05.001.

Breakwell, G. M., 2001: Mental models and social representations of hazards: The significance of identity processes. J. Risk Res. 4, 341-351, https://doi.org/10.1080/13669870110062730.
Breves, P., and H. Schramm, 2021: Bridging psychological distance: The impact of immersive media on distant and proximal environmental issues. Comput. Human Behav., 115, 106606, https://doi.org/10.1016/j.chb.2020.106606.

Brod, G., M. Werkle-Bergner, and Y. L. Shing, 2013: The influence of prior knowledge on memory: A developmental cognitive neuroscience perspective. Front. Behav. Neurosci., 7, 139, https://doi.org/10.3389/fnbeh.2013.00139.

Broomell, S. B., J.-F. Winkles, and P. B. Kane, 2017: The perception of daily temperatures as evidence of global warming. Wea. Climate Soc., 9, 563-574, https://doi.org/10.1175/WCAS-D-170003.1.

Brulle, R. J., J. Carmichael, and J. C. Jenkins, 2012: Shifting public opinion on climate change: An empirical assessment of factors influencing concern over climate change in the U.S., 20022010. Climatic Change, 114, 169-188, https://doi.org/10.1007/ s10584-012-0403-y.

Burgess, M. C. R., and G. E. Weaver, 2003: Interest and attention in facial recognition. Percept. Mot. Skills, 96, 467-480, https:// doi.org/10.2466/pms.2003.96.2.467.

Cai, W., and Coauthors, 2015: Increased frequency of extreme La Niña events under greenhouse warming. Nat. Climate Change, 5, 132-137, https://doi.org/10.1038/nclimate2492.

Canli, T., Z. Zhao, J. Brewer, J. D. E. Gabrieli, and L. Cahill, 2000: Event-related activation in the human amygdala associates with later memory for individual emotional experience. J. Neurosci., 20, RC99, https://doi.org/10.1523/ JNEUROSCI.20-19-j0004.2000.

Capstick, S. B., and N. F. Pidgeon, 2014: Public perception of cold weather events as evidence for and against climate change. Climatic Change, 122, 695-708, https://doi.org/10.1007/s10584013-1003-1.

-, L. Whitmarsh, W. Poortinga, N. Pidgeon, and P. Upham, 2015: International trends in public perceptions of climate change over the past quarter century. Wiley Interdiscip. Rev.: Climate Change, 6, 35-61, https://doi.org/10.1002/wcc.321.

Carmichael, J. T., and R. J. Brulle, 2017: Elite cues, media coverage, and public concern: An integrated path analysis of public opinion on climate change, 2001-2013. Env. Polit., 26, 232252, https://doi.org/10.1080/09644016.2016.1263433.

Catal, L. L., and J. M. Fitzgerald, 2004: Autobiographical memory in two older adults over a twenty-year retention interval. Mem. Cognit., 32, 311-323, https://doi.org/10.3758/BF03196861.

Chapman, D. A., B. Lickel, and E. M. Markowitz, 2017: Reassessing emotion in climate change communication. Nat. Climate Change, 7, 850-852, https://doi.org/10.1038/s41558-017-0021-9.

Conway, M. A., 2005: Memory and the self. J. Mem. Lang., 53, 594628, https://doi.org/10.1016/j.jml.2005.08.005.

Craik, F. I. M., 2006: Distinctiveness and memory: Comments and point of view. Memory and Emotion: Interdisciplinary Perspectives, B. Uttl, N. Ohta, and A. L. Siegenthaler, Eds., Blackwell, 425442.

Cunsolo, A., and N. R. Ellis, 2018: Ecological grief as a mental health response to climate change-related loss. Nat. Climate Change, 8, 275-281, https://doi.org/10.1038/s41558-018-0092-2.

Deffenbacher, K. A., B. H. Bornstein, S. D. Penrod, and E. Kiernan, 2004: A meta-analytic review of the effects of high stress on eyewitness memory. Law Hum. Behav., 28, 687-706, https:// doi.org/10.1007/s10979-004-0565-x.

Demski, C., S. B. Capstick, N. Pidgeon, R. G. Sposato, and A. Spence, 2017: Experience of extreme weather affects climate change mitigation and adaptation responses. Climatic Change, 140, 149-164, https://doi.org/10.1007/s10584-016-1837-4. 
Dessai, S., and C. Sims, 2010: Public perception of drought and climate change in southeast England. Environ. Hazards, 9, 340-357, https://doi.org/10.3763/ehaz.2010.0037.

DeSteno, D., R. E. Petty, D. D. Rucker, D. T. Wegener, and J. Braverman, 2004: Discrete emotions and persuasion: The role of emotion-induced expectancies. J. Pers. Soc. Psychol., 86, 43-56, https://doi.org/10.1037/0022-3514.86.1.43.

Donner, S. D., and J. McDaniels, 2013: The influence of national temperature fluctuations on opinions about climate change in the U.S. since 1990. Climatic Change, 118, 537-550, https:// doi.org/10.1007/s10584-012-0690-3.

Dunn, P. T., A. Y. E. Ahn, A. Bostrom, and J. E. Vidale, 2016: Perceptions of earthquake early warnings on the U.S. West Coast. Int. J. Disaster Risk Reduct., 20, 112-122, https:// doi.org/10.1016/j.ijdrr.2016.10.019.

Egan, P. J., and M. Mullin, 2012: Turning personal experience into political attitudes: The effect of local weather on Americans' perceptions about global warming. J. Polit., 74, 796-809, https://doi.org/10.1017/S0022381612000448.

Fauville, G., A. C. M. Queiroz, and J. N. Bailenson, 2020: Virtual reality as a promising tool to promote climate change awareness. Technology and Health, J. Kim and H. Song, Eds., Academic Press, 91-108.

Fischer, A., and K. Glenk, 2011: One model fits all?-On the moderating role of emotional engagement and confusion in the elicitation of preferences for climate change adaptation policies. Ecol. Econ., 70, 1178-1188, https://doi.org/10.1016/ j.ecolecon.2011.01.014.

Floyd, D. L., S. Prentice-Dunn, and R. W. Rogers, 2000: A metaanalysis of research on protection motivation theory. J. Appl. Soc. Psychol., 30, 407-429, https://doi.org/10.1111/ j.1559-1816.2000.tb02323.x.

Fownes, J. R., and S. B. Allred, 2018: Testing the Influence of recent weather on perceptions of personal experience with climate change and extreme weather in New York State. Wea. Climate Soc., 11, 143-157, https://doi.org/10.1175/WCAS-D-17-0107.1.

Frimer, J. A., L. J. Skitka, and M. Motyl, 2017: Liberals and conservatives are similarly motivated to avoid exposure to one another's opinions. J. Exp. Soc. Psychol., 72, 1-12, https:// doi.org/10.1016/j.jesp.2017.04.003.

Fritze, J. G., G. A. Blashki, S. Burke, and J. Wiseman, 2008: Hope, despair and transformation: Climate change and the promotion of mental health and wellbeing. Int. J. Ment. Health Syst., 2, 13, https://doi.org/10.1186/1752-4458-2-13.

Gavin, N. T., and T. Marshall, 2011: Mediated climate change in Britain: Scepticism on the web and on television around Copenhagen. Global Environ. Change, 21, 1035-1044, https:// doi.org/10.1016/j.gloenvcha.2011.03.007.

Geraci, L., and S. Rajaram, 2002: The orthographic distinctiveness effect on direct and indirect tests of memory: Delineating the awareness and processing requirements. J. Mem. Lang., 47, 273-291, https://doi.org/10.1016/S0749-596X(02)00008-6.

Ghosh, V. E., and A. Gilboa, 2014: What is a memory schema? A historical perspective on current neuroscience literature. Neuropsychologia, 53, 104-114, https://doi.org/10.1016/ j.neuropsychologia.2013.11.010.

Goebbert, K., H. C. Jenkins-Smith, K. Klockow, M. C. Nowlin, and C. L. Silva, 2012: Weather, climate, and worldviews: The sources and consequences of public perceptions of changes in local weather patterns. Wea. Climate Soc., 4, 132-144, https:// doi.org/10.1175/WCAS-D-11-00044.1.

Griffin, R. J., S. Dunwoody, and K. Neuwirth, 1999: Proposed model of the relationship of risk information seeking and processing to the development of preventive behaviors. Environ. Res., 80, S230-S245, https://doi.org/10.1006/enrs.1998.3940.

Grothmann, T., and F. Reusswig, 2006: People at risk of flooding: Why some residents take precautionary action while others do not. Nat. Hazards, 38, 101-120, https://doi.org/10.1007/s11069005-8604-6.

Hamilton, L. C., and M. D. Stampone, 2013: Blowin' in the wind: Short-term weather and belief in anthropogenic climate change. Wea. Climate Soc., 5, 112-119, https://doi.org/10.1175/ WCAS-D-12-00048.1.

—, M. Lemcke-Stampone, and C. Grimm, 2018: Cold winters warming? Perceptions of climate change in the North Country. Wea. Climate Soc., 10, 641-652, https://doi.org/10.1175/WCASD-18-0020.1.

Hart, W., D. Albarracín, A. H. Eagly, I. Brechan, M. J. Lindberg, and L. Merrill, 2009: Feeling validated versus being correct: A meta-analysis of selective exposure to information. Psychol. Bull., 135, 555-588, https://doi.org/10.1037/a0015701.

Hazlett, C., and M. Mildenberger, 2020: Wildfire exposure increases pro-environment voting within democratic but not republican areas. Amer. Polit. Sci. Rev., 114, 1359-1365, https://doi.org/10.1017/S0003055420000441.

Hoscheidt, S. M., B. Dongaonkar, J. Payne, and L. Nadel, 2013: Emotion, stress, and memory. The Oxford Handbook of Cognitive Psychology, D. Reisberg, Ed., Oxford Library of Psychology, Oxford University Press, 557-570.

Howe, P. D., and A. Leiserowitz, 2013: Who remembers a hot summer or a cold winter? The asymmetric effect of beliefs about global warming on perceptions of local climate conditions in the U.S. Global Environ. Change, 23, 1488-1500, https://doi.org/10.1016/j.gloenvcha.2013.09.014.

- H. Boudet, A. Leiserowitz, and E. W. Maibach, 2014: Mapping the shadow of experience of extreme weather events. Climatic Change, 127, 381-389, https://doi.org/10.1007/s10584014-1253-6.

_ J. R. Marlon, M. Mildenberger, and B. S. Shield, 2019: How will climate change shape climate opinion? Environ. Res. Lett., 14, 113001, https://doi.org/10.1088/1748-9326/ab466a.

Hunt, R. R., 2006: The concept of distinctiveness in memory research. Distinctiveness and Memory, R. R. Hunt and J. B. Worthen, Eds., Oxford University Press, 3-25.

Illeris, K., 2006: A comprehensive understanding of human learning. Human Learning: An Holistic Approach, P. Jarvis and S. Parker, Eds., Routledge, 87-100.

Kahan, D. M., H. Jenkins-Smith, and D. Braman, 2011: Cultural cognition of scientific consensus. J. Risk Res., 14, 147-174, https://doi.org/10.1080/13669877.2010.511246.

—, E. Peters, M. Wittlin, P. Slovic, L. L. Ouellette, D. Braman, and G. Mandel, 2012: The polarizing impact of science literacy and numeracy on perceived climate change risks. Nat. Climate Change, 2, 732-735, https://doi.org/10.1038/nclimate1547.

Kasperson, J. X., and R. E. Kasperson, 2005: Social Contours of Risk: Publics, Risk Communication and the Social Amplification of Risk. Earthscan, 370 pp.

Keller, C., M. Siegrist, and H. Gutscher, 2006: The role of the affect and availability heuristics in risk communication. Risk Anal., 26, 631-639, https://doi.org/10.1111/j.1539-6924.2006.00773.x.

Kesebir, S., and S. Oishi, 2010: A spontaneous self-reference effect in memory: Why some birthdays are harder to remember than others. Psychol. Sci., 21, 1525-1531, https://doi.org/10.1177/ 0956797610383436.

Klein, E. S., and R. H. Thurstan, 2016: Acknowledging long-term ecological change: The problem of shifting baselines. Perspectives 
on Oceans Past, K. Schwerdtner Máñez and B. Poulsen, Eds., Springer, 11-29.

Knobloch-Westerwick, S., and J. Meng, 2009: Looking the other way: Selective exposure to attitude-consistent and counterattitudinal political information. Commun. Res., 36, 426-448, https://doi.org/10.1177/0093650209333030.

Knuth, D., D. Kehl, L. Hulse, and S. Schmidt, 2014: Risk perception, experience, and objective risk: A cross-national study with European emergency survivors. Risk Anal., 34, 1286-1298, https://doi.org/10.1111/risa.12157.

Krosnick, J. A., 1988: Attitude importance and attitude change. J. Exp. Soc. Psychol., 24, 240-255, https://doi.org/10.1016/ 0022-1031(88)90038-8.

— , and D. F. Alwin, 1989: Aging and susceptibility to attitude change. J. Pers. Soc. Psychol., 57, 416-425, https://doi.org/ 10.1037/0022-3514.57.3.416.

Kunda, Z., 1990: The case for motivated reasoning. Psychol. Bull., 108, 480-498, https://doi.org/10.1037/0033-2909.108.3.480.

Laney, C., H. V. Campbell, F. Heuer, and D. Reisberg, 2004: Memory for thematically arousing events. Mem. Cognit., 32, 1149-1159, https://doi.org/10.3758/BF03196888.

Lawrence, J., D. Quade, and J. Becker, 2014: Integrating the effects of flood experience on risk perception with responses to changing climate risk. Nat. Hazards, 74, 1773-1794, https:// doi.org/10.1007/s11069-014-1288-z.

Lehner, F., and T. F. Stocker, 2015: From local perception to global perspective. Nat. Climate Change, 5, 731-734, https://doi.org/ 10.1038/nclimate2660.

Leiserowitz, A., 2006: Climate change risk perception and policy preferences: The role of affect, imagery, and values. Climatic Change, 77, 45-72, https://doi.org/10.1007/s10584-006-9059-9.

Levine, L. J., and S. L. Burgess, 1997: Beyond general arousal: Effects of specific emotions on memory. Soc. Cognit., 15, 157-181, https://doi.org/10.1521/soco.1997.15.3.157.

— grumpy overview. Soc. Cognit., 22, 530-554, https://doi.org/ 10.1521/soco.22.5.530.50767.

— A review and goal-relevance approach. Cognit. Emotion, 23, 833-875, https://doi.org/10.1080/02699930902738863.

Lin, N., K. Emanuel, M. Oppenheimer, and E. Vanmarcke, 2012: Physically based assessment of hurricane surge threat under climate change. Nat. Climate Change, 2, 462-467, https:// doi.org/10.1038/nclimate1389.

Lönnqvist, J.-E., and J. V. A. Itkonen, 2016: Homogeneity of personal values and personality traits in Facebook social networks. J. Res. Pers., 60, 24-35, https://doi.org/10.1016/j.jrp.2015.11.001.

Lorenzoni, I., and M. Hulme, 2009: Believing is seeing: Laypeople's views of future socio-economic and climate change in England and in Italy. Public Understanding Sci., 18, 383-400, https:// doi.org/10.1177/0963662508089540.

Lujala, P., H. Lein, and J. K. Rød, 2015: Climate change, natural hazards, and risk perception: The role of proximity and personal experience. Local Environ., 20, 489-509, https://doi.org/ 10.1080/13549839.2014.887666.

Maas, A., C. Wardropper, G. Roesch-McNally, and J. Abatzoglou, 2020: A (mis)alignment of farmer experience and perceptions of climate change in the U.S. inland Pacific Northwest. Climatic Change, 162, 1011-1029, https://doi.org/10.1007/s10584-020-02713-6.

Maloney, E. K., M. K. Lapinski, and K. Witte, 2011: Fear appeals and persuasion: A review and update of the extended parallel process model. Soc. Pers. Psychol. Compass, 5, 206-219, https://doi.org/10.1111/j.1751-9004.2011.00341.x.
McCright, A. M., R. E. Dunlap, and C. Xiao, 2014: The impacts of temperature anomalies and political orientation on perceived winter warming. Nat. Climate Change, 4, 1077-1081, https:// doi.org/10.1038/nclimate2443.

McDaniel, M. A., and L. Geraci, 2006: Encoding and retrieval processes in distinctiveness effects: Toward an integrative framework. Memory and Emotion: Interdisciplinary Perspectives, B. Uttl, N. Ohta, and A. L. Siegenthaler, Eds., Blackwell, 65-88.

Meijnders, A. L., C. J. H. Midden, and H. A. M. Wilke, 2001: Role of negative emotion in communication about $\mathrm{CO}_{2}$ risks. Risk Anal., 21, 955-966, https://doi.org/10.1111/0272-4332.215164.

Moore, F. C., N. Obradovich, F. Lehner, and P. Baylis, 2019: Rapidly declining remarkability of temperature anomalies may obscure public perception of climate change. Proc. Natl. Acad. Sci. USA, 116, 4905-4910, https://doi.org/10.1073/pnas.1816541116.

Myers, T. A., E. W. Maibach, C. Roser-Renouf, K. Akerlof, and A. A. Leiserowitz, 2013: The relationship between personal experience and belief in the reality of global warming. Nat. Climate Change, 3, 343-347, https://doi.org/10.1038/nclimate1754.

Nicholson-Cole, S. A., 2005: Representing climate change futures: A critique on the use of images for visual communication. Comput. Environ. Urban Syst., 29, 255-273, https://doi.org/ 10.1016/j.compenvurbsys.2004.05.002.

Ogunbode, C. A., G. Böhm, S. B. Capstick, C. Demski, A. Spence, and N. Tausch, 2019: The resilience paradox: Flooding experience, coping and climate change mitigation intentions. Climate Policy, 19, 703-715, https://doi.org/10.1080/14693062.2018.1560242.

_- R. Doran, and G. Böhm, 2020: Individual and local flooding experiences are differentially associated with subjective attribution and climate change concern. Climatic Change, 162, 2243-2255, https://doi.org/10.1007/s10584-020-02793-4.

O'Neill, B. C., and Coauthors, 2017: IPCC reasons for concern regarding climate change risks. Nat. Climate Change, 7, 28-37, https://doi.org/10.1038/nclimate3179.

Petersen, G. B., S. Klingenberg, R. E. Mayer, and G. Makransky, 2020: The virtual field trip: Investigating how to optimize immersive virtual learning in climate change education. Br. J. Educ. Technol., 51, 2099-2115, https://doi.org/10.1111/bjet.12991.

Petty, R. E., and J. T. Cacioppo, 1986: The elaboration likelihood model of persuasion. Advances in Experimental Social Psychology, L. Berkowitz, Ed., Vol. 19, Elsevier, 123-205, https://doi.org/10.1016/S0065-2601(08)60214-2.

— C. P. Haugtvedt, and S. M. Smith, 1995: Elaboration as a determinant of attitude strength: Creating attitudes that are persistent, resistant, and predictive of behavior. Attitude Strength: Antecedents and Consequences, R. E. Petty and J. A. Krosnick, Eds., Erlbaum, 93-130.

Piaget, J., and M. Cook, 1952: The Origins of Intelligence in Children. International Universities Press, 419 pp.

Pidgeon, N. F., R. E. Kasperson, and P. Slovic, 2003: The Social Amplification of Risk. Cambridge University Press, 448 pp.

Proulx, T., and S. J. Heine, 2010: The frog in Kierkegaard's beer: Finding meaning in the threat-compensation literature. Soc. Pers. Psychol. Compass, 4, 889-905, https://doi.org/10.1111/ j.1751-9004.2010.00304.x.

_, M. Inzlicht, and E. Harmon-Jones, 2012: Understanding all inconsistency compensation as a palliative response to violated expectations. Trends Cognit. Sci., 16, 285-291, https:// doi.org/10.1016/j.tics.2012.04.002.

Reisberg, D., 2006: Memory for emotional episodes: The strengths and limits of arousal-based accounts. Memory and Emotion: Interdisciplinary Perspectives, B. Uttl, N. Ohta, and A. L. Siegenthaler, Eds., Blackwell, 15-36. 
Renn, O., 2011: The social amplification/attenuation of risk framework: Application to climate change. Wiley Interdiscip. Rev.: Climate Change, 2, 154-169, https://doi.org/10.1002/wcc.99.

Reser, J. P., G. L. Bradley, and M. C. Ellul, 2014: Encountering climate change: 'Seeing' is more than 'believing'. Wiley Interdiscip. Rev.: Climate Change, 5, 521-537, https://doi.org/10.1002/wcc.286.

Ripberger, J. T., H. C. Jenkins-Smith, C. L. Silva, D. E. Carlson, K. Gupta, N. Carlson, and R. E. Dunlap, 2017: Bayesian versus politically motivated reasoning in human perception of climate anomalies. Environ. Res. Lett., 12, 114004, https:// doi.org/10.1088/1748-9326/aa8cfc.

Rogers, R. W., 1975: A protection motivation theory of fear appeals and attitude change. J. Psychol., 91, 93-114, https:// doi.org/10.1080/00223980.1975.9915803.

Rogers, T. B., N. A. Kuiper, and W. S. Kirker, 1977: Self-reference and the encoding of personal information. J. Pers. Soc. Psychol., 35, 677-688, https://doi.org/10.1037/0022-3514.35.9.677.

Ross, L., M. R. Lepper, and M. Hubbard, 1975: Perseverance in self-perception and social perception: Biased attributional processes in the debriefing paradigm. J. Pers. Soc. Psychol., 32, 880-892, https://doi.org/10.1037/0022-3514.32.5.880.

Schmidt, S. R., 1985: Encoding and retrieval processes in the memory for conceptually distinctive events. J. Exp. Psychol. Learn. Mem. Cognit., 11, 565-578, https://doi.org/10.1037/0278-7393.11.3.565.

- 1991: Can we have a distinctive theory of memory? Mem. Cognit., 19, 523-542, https://doi.org/10.3758/BF03197149.

Seligman, M. E. P., 1975: Helplessness: On Depression, Development, and Death. Freeman, $250 \mathrm{pp}$.

Shao, W., 2016: Are actual weather and perceived weather the same? Understanding perceptions of local weather and their effects on risk perceptions of global warming. J. Risk Res., 19, 722-742, https://doi.org/10.1080/13669877.2014.1003956.

_ perceptions of local weather conditions and climate change among residents in the U.S. Gulf Coast. Risk Anal., 36, 21362157, https://doi.org/10.1111/risa.12571.

Sheeran, P., P. R. Harris, and T. Epton, 2014: Does heightening risk appraisals change people's intentions and behavior? A metaanalysis of experimental studies. Psychol. Bull., 140, 511-543, https://doi.org/10.1037/a0033065.

Sisco, M. R., V. Bosetti, and E. U. Weber, 2017: When do extreme weather events generate attention to climate change? Climatic Change, 143, 227-241, https://doi.org/10.1007/s10584-017-1984-2.

Smith, N., and H. Joffe, 2009: Climate change in the British press: The role of the visual. J. Risk Res., 12, 647-663, https://doi.org/ 10.1080/13669870802586512.

— and _ 2013: How the public engages with global warming: A social representations approach. Public Understanding Sci., 22, 16-32, https://doi.org/10.1177/0963662512440913.

—_, and A. Leiserowitz, 2014: The role of emotion in global warming policy support and opposition. Risk Anal., 34, 937948, https://doi.org/10.1111/risa.12140.

Spence, A., W. Poortinga, C. Butler, and N. F. Pidgeon, 2011: Perceptions of climate change and willingness to save energy related to flood experience. Nat. Climate Change, 1, 46-49, https://doi.org/10.1038/nclimate1059.

Steentjes, K., and Coauthors, 2017: European perceptions of climate change (EPCC): Topline findings of a survey conducted in four European countries in 2016. Cardiff University Project Rep., 72 pp., http://orca.cf.ac.uk/98660/7/EPCC.pdf.

Stern, P. C., 2000: Toward a coherent theory of environmentally significant behavior. J. Soc. Issues, 56, 407-424, https://doi.org/ 10.1111/0022-4537.00175.
Sundblad, E.-L., A. Biel, and T. Gärling, 2007: Cognitive and affective risk judgements related to climate change. J. Environ. Psychol., 27, 97-106, https://doi.org/10.1016/j.jenvp.2007.01.003.

Swim, J., S. Clayton, T. Doherty, R. Gifford, G. Howard, J. P. Reser, P. C. Stern, and E. U. Weber, 2010: Psychology and global climate change: Addressing a multi-faceted phenomenon and set of challenges. American Psychological Association Doc., 108 pp., http://www.apa.org/science/about/publications/climatechange-booklet.pdf.

Talarico, J. M., K. S. LaBar, and D. C. Rubin, 2004: Emotional intensity predicts autobiographical memory experience. Mem. Cognit., 32, 1118-1132, https://doi.org/10.3758/BF03196886.

Taylor, A., W. B. de Bruin, and S. Dessai, 2014: Climate change beliefs and perceptions of weather-related changes in the United Kingdom. Risk Anal., 34, 1995-2004, https://doi.org/10.1111/risa.12234.

Tomaszczyk, J. C., M. A. Fernandes, and C. M. MacLeod, 2008: Personal relevance modulates the positivity bias in recall of emotional pictures in older adults. Psychon. Bull. Rev., 15, 191-196, https://doi.org/10.3758/PBR.15.1.191.

Tormala, Z. L., and D. D. Rucker, 2007: Attitude certainty: A review of past findings and emerging perspectives. Soc. Pers. Psychol. Compass, 1, 469-492, https://doi.org/10.1111/j.17519004.2007.00025.x.

van der Linden, S., 2014: On the relationship between personal experience, affect and risk perception: The case of climate change. Eur. J. Soc. Psychol., 44, 430-440, https://doi.org/10.1002/ejsp.2008.

van der Linden, S. L., 2015: The social-psychological determinants of climate change risk perceptions: Towards a comprehensive model. J. Environ. Psychol., 41, 112-124, https://doi.org/ 10.1016/j.jenvp.2014.11.012.

Wachinger, G., O. Renn, C. Begg, and C. Kuhlicke, 2013: The risk perception paradox-Implications for governance and communication of natural hazards. Risk Anal., 33, 1049-1065, https://doi.org/10.1111/j.1539-6924.2012.01942.x.

Washburn, A. N., and L. J. Skitka, 2017: Science denial across the political divide: Liberals and conservatives are similarly motivated to deny attitude-inconsistent science. Soc. Psychol. Pers. Sci., 9, 1948550617731500, https://doi.org/10.1177/1948550617731500.

Whitmarsh, L., 2008: Are flood victims more concerned about climate change than other people? The role of direct experience in risk perception and behavioural response. J. Risk Res., 11, 351-374, https://doi.org/10.1080/13669870701552235.

and S. B. Capstick, 2018: Perceptions of climate change. Psychology and Climate Change, S. Clayton and C. Manning, Eds., Academic Press, 13-33.

Yang, Z. J., L. N. Rickard, T. M. Harrison, and M. Seo, 2014: Applying the risk information seeking and processing model to examine support for climate change mitigation policy. Sci. Commun., 36, 1075547014525350, https://doi.org/10.1177/1075547014525350.

— M. Seo, L. N. Rickard, and T. M. Harrison, 2015: Information sufficiency and attribution of responsibility: Predicting support for climate change policy and pro-environmental behavior. J. Risk Res., 18, 727-746, https://doi.org/10.1080/13669877.2014.910692.

Yantis, S., 1993: Stimulus-driven attentional capture. Curr. Dir. Psychol. Sci., 2, 156-161, https://doi.org/10.1111/1467-8721.ep10768973.

Zaalberg, R., C. J. H. Midden, A. Meijnders, and T. McCalley, 2009: Prevention, adaptation, and threat denial: Flooding experiences in the Netherlands. Risk Anal., 29, 1759-1778, https://doi.org/10.1111/j.1539-6924.2009.01316.x.

Zuwerink, J. R., and P. G. Devine, 1996: Attitude importance and resistance to persuasion: It's not just the thought that counts. J. Pers. Soc. Psychol., 70, 931-944, https://doi.org/10.1037/ 0022-3514.70.5.931. 